\title{
COMISSÕES DE ÉTICA DE ENFERMAGEM EM INSTITUIÇÕES DE SAÚDE DE RIBEIRÃO PRETO
}

\author{
Cátia Ducati ${ }^{\top}$ \\ Magali Roseira Boemer ${ }^{2}$
}

Ducati C, Boemer MR. Comissões de ética de enfermagem em instituições de saúde de Ribeirão Preto. Rev Latino-am Enfermagem 2001 maio; 9(3):27-32.

O estudo teve como objetivo identificar hospitais de Ribeirão Preto que possuem Comissões de Ética de Enfermagem, estabelecidas de acordo com a Decisão do Conselho Regional de Enfermagem, verificar suas atividades e atribuições, os motivos da criação e observância à Legislação. Os resultados mostram que dos 11 hospitais visitados oito teriam obrigatoriedade de instituir Comissões e destes, apenas três a possuem, sendo que somente uma encontra-se efetivamente em atividade. 0 estudo possibilitou também identificar infrações éticas mais freqüentes assim como punições eventualmente aplicadas e evidenciou despreparo dos profissionais da Enfermagem em relação ao seu posicionamento perante essas Comissões.

UNITERMOS: comissão de ética, enfermagem

\section{NURSING ETHICS COMMITTEES IN RIBEIRÃO PRETO'S HEALTHCARE INSTITUTIONS}

The aim of this study was to identify hospitals in Ribeirão Preto, Brazil which have a Nursing Ethics Committee established according to the Decision of the Nursing Regional Council, to examine their activities and attributions, the reasons why they were created and the enforcement of legislation. The results have shown that from the eleven hospitals visited, eight ought to have instituted their Committees; however, only three had done it and only one of them was effectively active. The study made it possible to identify the most frequent infractions to ethics as well as the penalties occasionally inflicted and evidenced the unpreparedness of Nursing professionals as to their attitudes concerning Committees.

KEY WORDS: ethics committee, nursing

\section{COMISIONES DE ÉTICA DE ENFERMERÍA EN INSTITUCIONES DE SALUD DEL INTERIOR DEL ESTADO DE SÃO PAULO - BRASIL}

El estudio tuvo como objetivo identificar que hospitales de Ribeirão Preto tienen Comisiones de Ética de Enfermería, establecidas de acuerdo con la decisión del COREN; verificar sus actividades y atribuciones, los motivos de la creación y el cumplimiento de la legislación. Los resultados muestran que de los once hospitales visitados, 8 deberían conformar obligatoriamente Comisiones. De estos solamente 3 la poseen y solo una se encuentra en actividad. El estudio posibilitó también identificar algunas infracciones éticas más frecuentes así como los castigos eventualmente aplicados y mostró la falta de preparación de los profesionales de Enfermería en relación con su posición frente a las Comisiones.

TÉRMINOS CLAVES: comisiones de ética, enfermería

\footnotetext{
${ }^{1}$ Aluna do $3^{\circ}$ ano do curso de Graduação em Enfermagem. Bolsista de Iniciação Científica-CNPq, 1999, junto ao Projeto "Estudos fenomenológicos sobre a morte e o morrer"; '2Orientador. Professor Associado, aposentado, Escola de Enfermagem de Ribeirão Preto da Universidade de São Paulo, Centro Colaborador da OMS para o desenvolvimento da pesquisa em Enfermagem. Coordenadora de Projeto Integrado-CNPq. E-mail: boemer@eerp.usp.br
} 


\section{INTRODUÇÃO}

$N_{\text {a condição de aluna de Enfermagem interessei-me pela }}$ faceta ética do exercício profissional do enfermeiro e, de forma particular, pelo tema "Comissões de Ética de Enfermagem". Ao realizar algumas leituras, pude conhecer o estudo que relata que a Ética representa um atributo de consciência ou elemento formador do caráter, particularmente dos valores morais, que oferece ao indivíduo a polaridade do bem ou do mal, do certo ou errado, falso ou verdadeiro ${ }^{(1)}$.

São as Comissões de Ética de cada profissão que fiscalizam o seu exercício, discutem e divulgam seu Código de Ética. Assim, direcionei-me para leituras referentes a Comissões de Ética de Enfermagem, encontrando a publicação do Conselho Federal de Enfermagem (COFEN), a qual homologa a decisão do Conselho Regional de Enfermagem 003/96 (COREN) normatizando a criação dessas Comissões nas instituições de saúde no âmbito do Estado de São Paulo, tornando obrigatória sua criação em todas as instituições de saúde que possuam, no mínimo, dez enfermeiros. Essa decisão entrou em vigor a partir de 09 de janeiro de $1996^{(2)}$.

0 Regimento dessas Comissões estabelece normas referentes a sua constituição e eleição de seus membros, dispondo também sobre suas finalidades, a conduta a ser seguida no caso de infração ética para com o COREN e para com a instituição e as atribuições de cada membro ${ }^{(3)}$. De acordo com esse Regimento, as Comissões de Ética de Enfermagem são órgãos representativos do COREN, com função educativa, consultiva e fiscalizadora do exercício profissional e ético dos profissionais de enfermagem; são reconhecidas pela instituição e têm com esta uma relação de autonomia.

Sua criação é importante em qualquer instituição de saúde, independentemente do número de enfermeiros empregados e sua ausência abre espaço para que outros profissionais possam estar julgando questões éticas pertinentes à Enfermagem. Sua importância foi ressaltada, pela conselheira do $1^{\circ}$ Seminário sobre "Formação das Comissões de Ética de Enfermagem", realizado em maio/93. "A criação das Comissões de Ética de Enfermagem nos hospitais é de extraordinária importância; com elas, as sindicâncias sobre problemas profissionais de Enfermagem serão melhor encaminhadas e avaliadas. Com isso, teremos melhores condições de analisar a qualidade da assistência prestada e as condições de trabalho oferecidas" ${ }^{\prime 4)}$

Essa importância também é evidenciada em pesquisa realizada por uma enfermeira e coordenadora das Comissões de Ética de Enfermagem nas instituições de saúde do Estado de São Paulo; essa pesquisa abrangeu 958 instituições e detectou um aumento no número dessas Comissões. Assim, do total atualmente existente, apenas 200 deveriam, obrigatoriamente, manter uma Comissão, de acordo com os critérios previstos na Decisão do COREN - SP/DIR/003/96 ${ }^{(5)}$.
A ação de uma Comissão de Ética de Enfermagem frente à denúncias de infrações éticas foi avaliada por uma pesquisa que caracteriza os denunciantes e denunciados, as punições e denúncias mais freqüentes e os setores da instituição onde ocorre a maioria das infrações e o respectivo turno de trabalho ${ }^{(6)}$.

Após essas leituras planejei um estudo a ser realizado em instituições de saúde de Ribeirão Preto-SP com o objetivo de identificar aquelas que apresentam Comissões de Ética de Enfermagem, suas atividades e atribuições, os motivos que levaram à sua criação e a observância do Regimento publicado pelo COREn$\mathrm{SP}^{(3)}$. Cabe salientar ser esta uma cidade que é centro de referência de saúde da região nordeste paulista.

Para as instituições que não possuem Comissões de Ética de Enfermagem o objetivo foi averiguar o motivo da não criação, como é feita (e se é feita) a fiscalização do exercício ético profissional de Enfermagem e a conduta seguida por estas instituições frente a eventuais dilemas éticos.

\section{METODOLOGIA}

Com os objetivos traçados realizei, num primeiro momento, o levantamento dos hospitais da cidade de Ribeirão Preto identificando 11 hospitais, que passaram a ser representados, aleatoriamente, pelas letras $\mathrm{A}$ a $\mathrm{K}$.

Procedi à elaboração de dois tipos de formulários. 0 formulário A foi planejado para entrevista com a Presidente da Comissão de Ética de Enfermagem das instituições que possuíssem tal Comissão. 0 formulário B foi planejado para entrevista com a Enfermeira responsável pelo Setor de Enfermagem das instituições que não a possuíssem.

Após ser aprovado o Projeto dessa investigação pelo Comitê de Ética em Pesquisa da Escola de Enfermagem de Ribeirão Preto-USP, visitei cada hospital levando uma carta assinada por mim e pela orientadora do estudo, na qual constavam os objetivos do trabalho e a solicitação de sua colaboração. Apresentava também um Termo de Consentimento Informado, o qual foi assinado, no ato da entrevista, por mim e pela Presidente da Comissão ou pela Enfermeira responsável pelo setor de Enfermagem, informando a não necessidade de identificação pessoal e/ou institucional, a possibilidade de recusa e nosso compromisso de natureza ética para com os dados obtidos.

\section{RESULTADOS E DISCUSSÃO}

As 11 instituições compreendem hospitais gerais e especializados, de porte variável, estando a média entre 60-80 leitos, havendo extremos com 40 e também com mais de 700 leitos. 


\section{Comissões de Ética de Enfermagem}

Todas as entrevistadas têm conhecimento da Decisão do COREN-SP 003/96, a qual torna obrigatória a criação de Comissões de Ética de Enfermagem e relataram que consideram importante a existência dessas Comissões nas instituições de saúde.

Das 11 instituições visitadas, oito, obrigatoriamente, deveriam possuir Comissões de Ética de Enfermagem (segundo a Decisão do (OREN); apenas as instituições B, H e J, por possuírem em seu quadro de funcionários um número de enfermeiros inferior a dez, estariam dispensadas.

Das oito instituições que deveriam possuir suas Comissões, apenas três realmente as possuem ( $A, C$ e D). As outras cinco não estão cumprindo a Decisão do COREN.

As três Comissões de Ética de Enfermagem existentes são reconhecidas pelo COREN-SP, mas apenas uma encontra-se em atividade no momento. Assim, a Comissão do Hospital C não exerce suas funções perante o COREN pois, segundo sua Presidente, pelo fato de ter sido criada recentemente, (no último ano), seus membros estão despreparados para lidar com dilemas éticos. Portanto, neste primeiro momento, o trabalho dos membros da referida Comissão tem se voltado para um rigoroso estudo do Código de Ética de Enfermagem com vistas a esse preparo; nesse período, quaisquer problemas de natureza ética serão resolvidos internamente pelos membros da Comissão, sem formalizações em Atas e encaminhamentos ao COREN.

A Comissão do hospital $D$ não exerce quaisquer funções pois não há membros para sua composição devido a problemas internos da instituição, (grande número de demissões e renovação do quadro de funcionários). Assim, a análise e julgamento de todos os eventuais dilemas éticos caberão à Chefia de Enfermagem.

De acordo com o artigo $3^{\circ}$ da Decisão do COREN-SP, dentre as finalidades da Comissão de Ética de Enfermagem (além de zelar pelo exercício ético dos profissionais de Enfermagem nas instituições), estão também incluídas a educação, discussão, orientação e divulgação do Código de Ética dos profissionais de Enfermagem. Isto sugere que os profissionais não sentem-se preparados para lidar com questões de natureza ética numa Comissão.

Uma educação ética mais abrangente durante o curso de graduação precisa possibilitar reflexão a respeito de valores, visando 0 desenvolvimento da consciência ética dos estudantes. 0 conhecimento da Deontologia é muito importante para a formação do profissional de saúde e para o exercício de suas funções no âmbito do trabalho, pois fornece diretrizes para o seu comportamento. Desta forma, os conteúdos ministrados na disciplina de Deontologia durante a graduação deveriam permear o curso como um todo, desenvolvendo posturas essenciais para a compreensão dos deveres e responsabilidades durante o exercício da atividade profissional.

De acordo com o Regimento para criação de Comissões de Ética de Enfermagem ${ }^{(3)}$, os profissionais empregados na instituição candidatam-se espontaneamente para os cargos da Comissão; essa relação de candidatos é enviada ao COREN, ocorrendo posteriormente a eleição (todas as datas já são por ele pré-estabelecidas). Os profissionais de enfermagem votam em seus candidatos elegendo, então, os representantes da Comissão de Ética de Enfermagem.

A análise dos dados obtidos permite observar que essa eleição não vem ocorrendo devido à relutância dos profissionais em se candidatarem, ficando, assim, a Comissão desprovida de membros (como é o caso do hospital D). Às vezes, alguns profissionais de enfermagem são simplesmente comunicados pela Enfermeira-chefe que, a partir de um dado momento, passaram a integrar a Comissão de Ética de Enfermagem(como é o caso do hospital I).

Os membros da Comissão de Ética de Enfermagem do hospital A exercem suas funções na Comissão e perante o CORENSP. Reúnem-se e discutem problemas relacionados aos funcionários, às dificuldades percebidas por eles e também aos problemas éticos. Estes últimos são avaliados pelos membros desta Comissão e, dependendo de sua gravidade, são posteriormente encaminhados ao COREN-SP. Uma observação importante é que a Comissão desse hospital foi criada em 1998 e, até este momento, segundo a entrevistada, não houve infrações éticas que devessem ser encaminhadas ao COREN-SP, pois não são de alta gravidade.

A entrevistada da instituição $\mathrm{K}$ mencionou que está sendo providenciada a criação da Comissão de Ética de Enfermagem, mas em prazo indeterminado. As outras quatro instituições que não estão cumprindo a Decisão do COREN informaram que estão providenciando a criação de suas Comissões para este ano de 1999; a entrevistada do hospital $D$ também está providenciando, para este ano, a reorganização de sua Comissão de Ética de Enfermagem e, posteriormente, o exercício das funções de seus integrantes.

\section{Motivos para criação (ou não) de Comissões de Ética de Enfermagem}

A Tabela 1 evidencia os motivos que três instituições apresentam para terem criado suas Comissões de Ética de Enfermagem. 
Tabela 1 - Motivos apresentados para criação de Comissões de Ética de Enfermagem, segundo as entrevistadas. Ribeirão Preto, 1999

\begin{tabular}{|c|c|c|c|}
\hline MOTWOS & NÚMERC & ITUाర̧๐̃ & RCENTAGGEP \\
\hline Exigência do COREN & 2 & {$[, 0$} & $66,7 \%$ \\
\hline Como Auxilio aos Profissionais & 1 & A & $33,3 \%$ \\
\hline TOTÁL & 3 & & $100 \%$ \\
\hline
\end{tabular}

As cinco instituições que não cumprem a Decisão do COREN referem estar providenciando a criação de suas Comissões. A Tabela 2 permite observar os motivos alegados por essas instituições para a não criação de suas Comissões.

Tabela 2 - Motivos alegados para a não instituição das Comissões de Ética de Enfermagem, segundo as entrevistadas. Ribeirão Preto, 1999

\section{MOTHOS}

\section{NÚMERO INSTITUIÇÕES PORCENTAGGEM}

$\begin{array}{lccc}\begin{array}{l}\text { Existência de assuntos mais } \\ \text { importantes }\end{array} & 1 & \mathrm{I} & 20 \% \\ \begin{array}{l}\text { Discordância com as normas } \\ \text { estabelecidas }\end{array} & 1 & \mathrm{~K} & 20 \% \\ \begin{array}{l}\text { Ansência de candidatos } \\ \text { Obrigatoriedade recente }\end{array} & 1 & \mathrm{G} & 20 \% \\ \text { TOTăL } & 2 & \mathrm{E}, \mathrm{F} & 40 \% \\ & 5 & & 100 \%\end{array}$

Cabe mencionar novamente que as instituições $\mathrm{B}, \mathrm{H}$ e J não possuem suas Comissões de Ética de Enfermagem pois apresentam em seus quadros de funcionários número de enfermeiros menor que dez.

Pensando, então, na importância da criação de Comissões de Ética de Enfermagem, principalmente no reconhecimento dessa importância pelas entrevistadas, verifica-se que os motivos alegados por elas (como a exigência por parte do COREN, obrigatoriedade recente, ausência de candidatos, entre outros) não são justificados, pois estes motivos deveriam estar voltados para a necessidade de se possuir essa Comissão, zelando pelo exercício ético da profissão e assegurando uma postura pertinente aos valores humanos de todos os envolvidos no ato de cuidar.

\section{Fiscalização do Exercício Ético Profissional de Enfermagem}

A fiscalização do exercício ético profissional de Enfermagem está voltada para o controle da assistência prestada, com o objetivo de estar detectando falhas, buscando sempre uma boa qualidade. Essa fiscalização, segundo as entrevistadas, é essencial em dez das 11 instituições de saúde visitadas; apenas no hospital B ela não é realizada.

\section{Conduta frente às Infrações Éticas}

Através da fiscalização do exercício profissional de Enfermagem é possível detectar infrações éticas cometidas pelos profissionais de qualquer categoria. Essas infrações, segundo as entrevistadas, compreendem qualquer deslize ético, ou seja, qualquer falha cometida pelos profissionais de enfermagem que infrinja 0 Código de Ética da profissão. Em duas instituições não houve referência a infrações éticas, sendo elas, a instituição $B$ (que relatou não haver fiscalização do exercício ético profissional de Enfermagem), e a instituição J, devido ao fato da recém-admissão da enfermeira responsável pelo setor de Enfermagem; assim, durante o curto período em que está neste cargo, segundo seu relato, não houve infrações éticas cometidas pelos profissionais de Enfermagem dessa instituição.

Nas outras nove instituições, quando há ocorrências de infrações éticas, são aplicadas punições que dependem da gravidade da falta cometida. A instituição K se baseia na "educação em serviço" (segundo a entrevistada), ou seja, frente à infração, apura-se o fato, ouve-se 0 acusado e o infrator deverá pesquisar na literatura sobre a falta cometida e expor o que encontrou a outros profissionais de Enfermagem, levando-o, assim, a reconhecer o motivo que 0 levou a errar. Frente a faltas mais graves ou recidivas do mesmo funcionário são aplicadas punições mais severas. Quando há dúvidas na apuração da falta é solicitada ajuda ao COREN para análise. A conduta seguida por outras cinco instituições, inclusive a instituição J, é a apuração dos fatos, através de conversas com os acusados e acusadores ou através de questionários, seguida de análise desses dados e de sua gravidade e, posteriormente, aplicação de punições.

A instituição I procede da mesma forma descrita acima e, se for preciso (dependendo da gravidade da falta cometida), faz sindicância e age perante às infrações como se já possuísse sua Comissão de Ética de Enfermagem; já elaborou a chapa para eleição dos membros da Comissão, faltando apenas formalizar sua criação perante o COREN-SP.

As instituições A e C também seguem a mesma conduta; as punições são aplicadas pelos próprios membros da Comissão, sendo encaminhados ao COREN apenas os casos de alta gravidade. Cabe ressaltar aqui que a instituição A envia ao COREN as notificações formalizadas em Atas, bem como os problemas éticos de alta gravidade. Nessas duas instituições as infrações éticas chegam ao conhecimento dos membros de suas respectivas Comissões da seguinte forma:

- instituição A - durante a supervisão, realizada pelas enfermeiras, da equipe de Enfermagem;

- instituição $C$ - através das passagens de plantão, reclamações feitas por médicos, pacientes e outros funcionários da instituição ou através de um questionário respondido pelos pacientes. 
As pessoas encarregadas da análise dos problemas éticos se reúnem periodicamente e essa periodicidade varia de acordo com cada instituição, conforme observa-se na Tabela 3.

Tabela 3 - Periodicidade das reuniões para análise de problemas éticos segundo os onze Hospitais visitados. Ribeirão Preto, 1999

\section{PERIODICIDADE}

\begin{tabular}{|c|c|c|c|}
\hline Mensais & 5 & $A_{1} C_{1} F_{1}, G_{1}, D$ & $45,42 \%$ \\
\hline Bimestrais & 1 & H & $9,1 \%$ \\
\hline Quinzenais & 1 & $k$ & $9,1 \%$ \\
\hline Semanais & 2 & $\left.I_{1}\right\rfloor$ & $18,18 \%$ \\
\hline Durante a passagem de Plantão & 1 & $E$ & $9,1 \%$ \\
\hline Não há reuniões & 1 & B & $9,1 \%$ \\
\hline TOTÁL & 11 & & $100 \%$ \\
\hline
\end{tabular}

Cabe ressaltar que as instituições $\mathrm{A}$ e $\mathrm{C}$, que possuem Comissão de Ética de Enfermagem, cumprem os artigos $18^{\circ}$ e $19^{\circ}$ do Regimento para Criação de Comissões de Ética de Enfermagem, em relação à periodicidade das reuniões, que devem ser mensais ou em caráter extraordinário, quando houver necessidade.

\section{Problemas Éticos mais Comuns}

Cada entrevistada relatou os problemas éticos mais comuns em sua instituição. A maioria desses problemas concentrase na postura inadequada dos profissionais e nas questões referentes à medicação.

A postura inadequada dos profissionais compreende:

- comentários feitos pelos profissionais, sobre casos de pacientes, a outros profissionais ou a amigos;

- mau relacionamento entre funcionários;

- demora no atendimento aos pacientes;

- mau atendimento aos pacientes (atendimento rápido, sem vontade). Os problemas referentes à medicação compreendem:

- administração de medicamentos errados;

- administração de medicamentos a pacientes errados;

- administração de medicamentos em horários errados;

- não registro de medicação administrada, implicando em nova administração, com super dosagem para o paciente.

A instituição $H$ relatou como problema ético atual a permanência de grande número de atendentes em seu quadro de funcionários e, nesse sentido, encontra-se sob rigorosa pressão por parte do COREN-SP, tendo inquérito aberto sobre este assunto; está também sob essa rigorosa pressão a instituição I, mas relacionada ao não cumprimento da Decisão do COREN-SP 003/96.

mais comuns.

Tabela 4 - Problemas éticos mais comuns encontrados em onze hospitais, segundo as entrevistadas. Ribeirão Preto, 1999

\section{PROBLEMÁS ÉTICOS}

Postura inadequada dos profissionais

Erros de medicação

Permanência dos atendentes

Stress médico com a enfermagem

Não cumprimento da decisão do COREN

Falta de assiduidade dos funcionários

\section{NÚMERO PORCENTRGEM}

Punições

São aplicadas punições de acordo com cada infração ética. As punições das instituições $\mathrm{He} \mathrm{J}$, as quais são dispensadas pela Decisão do COREN-SP da criação de Comissões de Ética de Enfermagem, são aplicadas pela própria instituição. As instituições que não estão cumprindo a Decisão do COREN-SP, mas estão providenciando suas respectivas Comissões, também aplicam punições frente à gravidade dos problemas éticos.

A instituição D, cuja Comissão não exerce suas funções por falta de membros, também é responsável por aplicar as punições, o mesmo acontecendo com a instituição C, na qual sua Comissão também não exerce suas funções; portanto, não estão sendo enviadas ao COREN as Atas e infrações.

As punições referentes à instituição $A$, que possui sua Comissão em atividade, são também aplicadas pela própria instituição, não havendo punição por parte do COREN-SP, pois, segundo a entrevistada, as infrações éticas cometidas não são de alta gravidade e, portanto, não há necessidade de encaminhá-las ao COREN-SP.

As duas instituições que apresentam Comissões de Ética de Enfermagem, (instituições A e C) não agem de acordo com o Regimento $^{(3)}$ para criação dessas Comissões. Segundo esse Regimento, as Comissões são órgãos representativos do COREN, são reconhecidas pelas instituições, mas possuem com ela uma relação de autonomia; desta forma, a Comissão deve informar a instituição de suas atividades e de todos os relatos concluídos, encaminhados ao COREN ou arquivados.

De acordo com o artigo $9^{\circ}$ desse Regimento, a Comissão deve realizar sindicância frente a qualquer denúncia de infração ética; nessa sindicância são ouvidas as pessoas envolvidas e o caso é analisado. Constatados indícios de possível infração ética, a Comissão deve encaminhar o relatório da sindicância ao COREN-SP, o qual realiza nova sindicância, ouvindo os envolvidos, analisando o caso e emitindo um parecer. Se realmente for constatada infração 
ética, o Conselho instaura o processo ético que culminará com absolvição ou condenação do denunciado e aplicação de penalidade.

A análise dos dados evidencia que as punições mais freqüentes encontradas nas instituições foram: advertência verbal $(36,3 \%)$, advertência escrita $(31,8 \%)$, suspensão $(13,6 \%)$, demissão $(9,1 \%)$, transferência de hospital e estudo sobre 0 assunto (ambas com 4,6\%).

\section{CONCLUSÃO}

Após apresentar os resultados dessa investigação concluo que a situação das Comissões de Ética de Enfermagem na cidade de Ribeirão Preto é ainda incipiente, dado que, apesar da obrigatoriedade, os hospitais não as instituem, deixando de lado a importância da atuação dessas Comissões.

A formação dessas Comissões, suas funções e seu Regimento foram discutidos, recentemente, no $2^{\circ}$ Encontro das Comissões de Ética de Enfermagem do Estado de São Paulo, realizado em outubro/99, no Hospital Paulistano-SP. Nesse evento também foram propostas recomendações acerca da implementação da Resolução COFEN n 172, os aspectos legais da denúncia e possíveis alterações no Regimento das Comissões de Ética de Enfermagem (como mudança no número de membros das Comissões, conforme a população de Enfermagem de cada instituição e maior flexibilidade nas datas de realização de eleição e posse, entre outras) ${ }^{(7)}$.

Esse estudo evidencia que os profissionais relutam em se candidatar a cargos na Comissão de Ética de Enfermagem por sentirem-se despreparados para lidar com questões éticas e,

\section{REFERÊNCIAS BIBLIOGRÁFICAS}

1. Gomes JCM. 0 ensino de Ética dos profissionais de saúde. Rev Bioética 1996; 4(1):53-64.

2. Conselho Federal de Enfermagem (COFEN) (BR). Autarquia Federal -Lei 5905/73. Rio de Janeiro; 1996.

3. Conselho Regional de Enfermagem (COREN) (SP). Regimento para a criação, formação e funcionamento das Comissões de Ética de Enfermagem. São Paulo; 1996. sobretudo, pela falta de conhecimento acerca do Código de Ética da própria profissão. Vejo, portanto, na condição de aluna do $3^{\circ}$ ano do Curso de Graduação em Enfermagem, que essa falta de conhecimento e possível despreparo possa ter sua gênese durante a Graduação.

A Ética é uma disciplina essencial no período de formação do profissional e se constitui em atributo de consciência formador do caráter, possibilitando uma reflexão a respeito de valores morais e trazendo conhecimento em relação à nossa profissão, direitos e deveres. É necessário que mais espaços sejam abertos durante a Graduação para a discussão de casos clínicos relacionados à ética e para um estudo mais profundo do Código de Ética de Enfermagem. No percurso da graduação, as questões éticas emergem advindas das especificidades das diferentes clínicas (pediátrica, obstétrica, cirúrgica e outras tantas). Esses momentos são ricos e fecundos e precisam ser fortalecidos, pois revestem-se de grande potencial acadêmico para a construção de uma consciência ética. Nesse sentido, a área da Bioética pode ser o fio condutor que fundamente discussões dessa natureza.

É necessário que haja reciclagem dos profissionais em atividade, de forma que possam obter novos conhecimentos e estejam sempre reconstruindo o já aprendido a partir dos avanços nas várias esferas do conhecimento, estando, assim, capacitados para o exercício profissional em suas várias dimensões.

Finalizando este estudo posso concluir que desenvolver esse trabalho de Iniciação Científica muito contribuiu para meu crescimento acadêmico, abrindo novos caminhos para outros estudos a serem desenvolvidos por alunos e profissionais de enfermagem.

4. Arone EM. O COREN promove encontros para debater Comissões de Ética de Enfermagem. Bol Inf, COREN 1993 junho; 17:6.

5. Chamma R. Coordenação faz balanço das Comissões de Ética. Jornal do COREN-SP nov./dez. 1997; 20(13):14-5.

6. Mendes HWB, Caldas AL Jr. Infrações éticas envolvendo pessoal de enfermagem. Rev Latino-am Enfermagem dezembro 1999; 7(5):5-13.

7. Conselho Regional de Enfermagem (COREN) (SP). Atos Normativos - Resoluções. Rio de Janeiro; 1994. 